\title{
Orta Anadolu'da Yetiştirilen Bazı Mentha Türleri Üzerinde Bir Araştırma
}

\author{
Une Etude sur Quelques Espéces de Menthe \\ Cultivées en Anatolie Centrale
}

\section{Mekin TANKER*, Orhan AKI**, Bilge ŞENER*, Osman SONER*}

Türkiye'nin nane yağ ${ }_{1}$ (Oleum Menthae) tüketimi yıldan yıla artmaktadır. 1960-70 yılları arasında yılda ortalama 2-3 ton kadar tüketilen bu uçucu yağın ithalat miktarı 1972 de 8294 ve 1973 te $10.719 \mathrm{~kg}$ a yükselmiştir. 1974 yılındaki ithalatımız $6593 \mathrm{~kg}$ ve 1975 teki $7277 \mathrm{~kg} \mathrm{dir}$.

Yurdumuzda, yılda 8-10 ton kadar mentol ve 2 ton kadar da mentil valeriyanat kullanıldığı dikkate alınırsa, Mentha türlerinin kültürünün kendi çapında önem kazanmış bulunduğu açıkça ortaya çıkacaktır.

Her ne kadar, mentol, sentez yoluyla da elde edilebilen bir ham madde ise de, \% 80-90 mentol taşıyan uçucu yağlardan kristallendirme ile bu maddenin elde edilişi bu gün için de geçerli bir yoldur ve doğal mentol, sentetik mentole oranla, özellikle stabilite yönünden, daima tercih edilen bir ürün olmakta devam etmektedir.

Türkiye'de yalnız yurt içinde kullanmak amacı ile ve yukardaki değerler dikkate alındığında, yılda 25-30 ton nane yağı elde edilmesi gerekmektedir. Buna göre bu gün için en azından 3000-4000 dekarlık bir ekim alanına gereksinme duyulmaktadır.

Türkiye'de doğal olarak yetişen Mentha türlerinden $M$. pulegium'un çeşitli bölgelerden toplanan örnekleri üzerinde $(1,2,3,5)$ yapılan araştırmalar, bu türden elde edilen yağın \% 50-60 kadarının pulegon olduğunu kanitlamaktadır. Pulegon, mentol yarısentezinin ilk maddelerinden biridir.

Redaksiyona verildiği tarih: 27 Ocak 1976.

* Farmakognozi Kürsüsü, Eczacillk Fakültesi, Ankara Úniversitesi.

** Teknik Ziraat Müdürlüğü, Isparta. 
Anadolu'da doğal olarak yetişmekte olan M.longifolia, M.aquatica, M.tomentosa türleri üzerinde başlatılmış bulunan çalı̧̧malar henüz tamamlanmamıș bulunmakla beraber bu türlerin de bazı ketonlar yönünden zengin olan uçucu yağlar taşıdığı ve özellikle yarı sentez yönünden önemli olduğu şimdiden bilinmektedir.

Mentol bakımından zengin türlerden Mentha piperita'nın bazı, bölgelerde, yaygın olmayan kültürü yapılmaktadır. Ankara civarında yapilan kültürden elde edilen uçucu yağın \% 44.0 (2) ve Akhisar'da yapılan bir kültürden elde edilen uçucu yağın da \% 49.4 (4) total mentol taşıdığı önceden yapılmış olan araştırmalarla saptanmış bulunmaktadır, Bu miktarlara ve araştırmalarda verilen diğer değerlere göre adı geçen kültürlerden elde edilen uçucu yağlar, kodeks ve farmakope standartlarına uygunluk göstermemektedir.

Şimdiye kadar yapılan ve yayınlanmış bulunan araştırmalara göre farmasötik standartlara uygun uçucu yağ veren ilk kültür Isparta'da yapılmıştır. Bu bölgede 1970 yılında dikimi yapılan ve iyi gelişmiş M.piperita var. officinalis, f. rubescens (Mitcham nanesi), henüz çiçek açarken biçilmiş ve bu bitkilerden elde edilen uçucu yağda,

$\% 62.2$ total mentol

$\% 48.3$ serbest mentol

$\% 13.9$ mentil asetat

$\% 13.1$ menton

$\% \quad 4.3$ mentofuran

bulunduğu saptanmıştır (6). Fiziksel özellikleri de bu uçucu yağın farmasötik standartlara uygun olduğunu göstermektedir.

Bu araştırmada, yukarda adı geçen "Mitcham" türü dahil 3 Mentha türü ile yapılan bazı kültür ve üretim denemeleri değerlendirilmeğe çalışılmıştır.

Dikimi yapılan Mentha türlerinden 5 hususun incelenmesi amaçlanmıştır;

1- Isparta'da yılda 2 biçim yapmanın mümkün olup olmadığı,

2- Mentha türlerinden, özellikle, Mitcham nanesinden, bir defa dikildikten sonra, en çok 3 yil ürün alınabileceği bilindiğine göre, Mentha dikilmiş bir tarlaya, bitkiler söküldükten sonra tekrar Mentha dikilip dikilemiyeceği, 
3- Tarlayı seyreltmenin verim ve kalite üzerine etkisi,

4 - Taze halde distillenen bitkilerle soldurulmuş bitkilerin uçucu yağ verimi bakımından karşılaştırılması.

5- Mitcham nanesinin diğer türlerle, uçucu yağ verimi ve kalitesi yönünden karşılaştırılması.

\section{MATERYAL VE YÖNTEM}

$\mathrm{Bu}$ araştırmada 3 nane türü üzerinde çalışılmıştır:

1- Mentha piperita var. officinalis f. rubescens (Mitcham nanesi): 1970 yilında Hamburg'tan getirtilerek Isparta civarına dikilmiş, çeliklerin stolonlarından, Isparta - Kule önü mevkiinde üretilmiş örnekler*.

2- Aynı bitkinin Ankara'da Eczacılık Fakültesi bahçesine dikilen örnekleri.

3- Ege Úniversitesi Ziraat Fakültesi, Agroekoloji Kürsüsü bahçesinde üretilmiş ve buradan 1975 yılında getirilip dikilmiş Ukraine 541 tipi Mentha piperita**.

4- Yine aynı koşullarda getirilip dikilmiş Polymentha tipi Mentha piperita**.

Hazırlanan parsellerden elde edilen drog miktarı, dekar başına yaş nane olarak hesaplanmıştır. Toplanan naneler bekletilmeden su buharı distilasyonuna tabi tutulmuş ve uçucu yağ verimi yine yaş nane üzerinden hesaplanmıştır. Distilasyon için 80 litre kapasiteli, taşınabilir, bakır bir imbik kullanılmış ve imbik içindeki su, odun ateşiyle isıtılmıştır. Böylece tarla yakınında ve köylünün kolayca sağl1yacağı gereçlerle elde edilecek verimin hesaplanmasına çalışılmı̧̧ır.

Elde edilen uçucu yağların analizi Gaz kromatografisi ile yapılmıştır.

* Bitkinin temini ve Kuleönünde kültüre alınması hususunda yardımlarını esirgemiyen Sayın Av. Ersun Ergöz'e teșekkürü borç biliriz,

** Bitkilerin temini ve Isparta'da yetiştirilmesi bakımından yardımlarını esirgemiyen Sayın Doç.Dr. Ayhan Ceylan'a teșekkürü borç biliriz. 


$\begin{array}{ll}\text { Aparey } & : \text { Gas chromatograph Packard } 7400 \\ \text { Dedektör } & : \text { FID } \\ \text { Kolon } & : 5,5 \mathrm{~mm} \text { çap, } 2 \mathrm{~m} \text { uzunlukta, cam } \\ \text { Stasyoner faz } & : \% 20 \text { Carbowax } 20 \mathrm{M} \\ \text { Adsorban } & : \text { Chromosorb P. } \\ \text { Isı } & : 140^{\circ} \mathrm{C} \text { izotermal } \\ \text { Dedektör 1sısı } & : 150^{\circ} \mathrm{C} \\ \text { Enjektör ısısı } & : 150^{\circ} \mathrm{C} \\ \text { Taşıyııı gaz } & : \text { Azot }(40 \mathrm{ml} / \text { dak. }) \\ \mathrm{H}_{2} \text { geçiş hızı } & : 35 \mathrm{ml} / \text { dak. } \\ \text { Hava geçiş hızı } & : 400 \mathrm{ml} / \text { dak. }\end{array}$

\section{BULGULAR}

1- Biçim denemeleri: $\mathrm{Bu}$ denemelerin amacı Mitcham nanesinden Isparta'da bir yilda 2 ürün almanın mümkün olup olmadığını saptamaktır. Bu amaçla 1974 yılında dikilen nane parsellerinden iki ayrı kısım denemeye alınmıştır. Birinci kısımdan ilk biçim 3.6.1975 te ikinci biçim 18.8.1975 te yapılmıştır. İkinci kısım ise 31.7.1975 4.8.1975 tarihleri arasında biçilmiştir.

a) Birinci kısım kültürden ilk biçim yapıldığı zaman nanelerin boyu ancak $35-45 \mathrm{~cm}$ ye ulaşmıştır. Daha geç biçim yapılsa idi nane boyları 5-10 $\mathrm{cm}$ daha artabilirdi, ancak bu defa da ikinci biçim için daha da az bir zaman bırakılmış olacaktı. İkinci biçim, ikinci defa büyüyen nanelerin çiçeklenme başlangıcında yapılmıştır. Çiçeğe geçmiş olmasına rağmen bu nanelerin boyu, tek biçime uygulananlara oranla daha kısadır.

Birinci biçimde yaş nane verimi dekar başına $2000 \mathrm{~kg}$, ikinci biçimde $1000 \mathrm{~kg}$ olarak hesaplanmıştır. Birinci biçimde \% 0.12 ve ikinci biçimde \% 0.38 uçucu yağ elde edilmiştir. İlk biçimde az miktarda yă̆ elde edilişi, distilasyonun yapılı̧ı sırasında, hatalı işlemden ileri gelmiştir. Bu nedenle, denemede uçucu yağ verimi hesaba katılmiyacaktır.

İki biçimden elde edilen yağlar karıştırılmış ve bu yağın gaz kromatografisi ile yapilan analizinde \% 44.79 mentol, \% 4.21 mentil asetat, \% 29.21 menton ve \% 3.33 mentofuran taşıdığı saptanmıştır. 
b) İkinci kısım kültürde naneler çiçeklenme başlangıcında biçilmiştir. Bu biçimde yaş nane verimi $2070 \mathrm{~kg}$ olarak hesaplanmıştır. Bu nanelerin biçilir biçilmez yapilan distilasyonu ile \% 0.32 oranıda yağ elde edilmiştir.

Elde edilen yağın, gaz kromatografisi ile yapılan analizinde, \% 38.80 mentol, \% 5.63 mentil asetat, \% 33.96 menton, \% 2.69 mentofuran taşıdığı saptanmıștır.

2- Tarla verim denemesi: Isparta'da 1973 yilında dikilmiş bulunan nanelerin bir kısmı $\left(80 \mathrm{~m}^{2}\right)$ sökülerek 1975 yilında yeniden dikim yapıldı. 17.8,1975 tarihinde biçimi yapılan naneler iyi gelişmiş değildi. Bu denemede dekar başına $815 \mathrm{~kg}$ yaş nane alındiğı ve bu nanelerin \% 0.38 uçucu yağ taşıdı̆̆ı hesaplanmıştrr.

Elde edilen uçucu yağın, gaz kromatografisiyle yapilan analizinde, $\% 38.63$ mentol, $\% 6.83$ mentil asetat, $\% 32.32$ menton, $\% 2.54$ mentofuran taşidığı saptanmıştır.

3- Seyreltmenin verim ve kalite üzerine etkisi: Isparta da 1973 yilında dikilmiş bulunan naneden $60 \mathrm{~m}^{2}$ lik bir alan, çapa siravari seyreltmeye tabi tutuldu. 7.8.1975 tarihinde henüz çiçek açmadan biçilen bu kısımdan alınan yaş nane miktarı dekar başına 1160 $\mathrm{kg}$ olarak hesaplanmış ve bu nanelerin biçilir biçilmez yapılan distilasyonu ile \% 0,42 oranında uçucu yağ elde edilmiştir.

Elde edilen yağın, gaz kromatografisiyle yapılan analizinde \% 38.67 mentol, \% 5.73 mentil asetat, \% 33.92 menton ve \% 1.71 mentofuran taşıdiğı saptanmıştır.

4- Uçucu yağ verim araştırması: Bu denemeler Ankara'da A.Ü. Eczacılık Fakültesi bahçesindeki deneme parselinde yetiştirilen Mitcham nanesi ile yapılmıştır. 1975 yılı Nisan başında dikilen naneler aynı yıl Temmuz ayı son haftasında gelişmiş ama henüz çiçek açmağa başlanmışken biçilmiş ve bir kısmı bekletilmeden, bir kısmı bir gün ve bir gece toprak üstünde bekletildikten sonra distillenerek, herbirinde uçucu yağ verimi ve elde edilen uçucu yağdaki bellibaşlı oksijenli monoterpenlerin miktar tayini yapılmıstır.

Bekletmeden distillenen nanelerden \% 1.0 oranında uçucu yă elde edilmiş ve gaz kromatografisiyle bu yağın \% 43.98 mentol, \% 4.56 mentil asetat, \% 32.48 menton, $\% 0.79$ mentofuran taşıdığ tanmıştır. 
1 gün ve 1 gece toprak üzerinde bekletildikten sonra distillenen nanelerde ise uçucu yağ verimi \% 2.4 tür. Bu yağın \% 41.07 sinin mentol, \% 3.05 inin mentil asetat, \% 35.37 sinin menton ve \% 1.06 sının mentofuran olduğu saptanmıştır.

Toplanıp kurutulan nanelerden ise \% 4.0 oranında uçucu yă elde edilmiş ve bu yağın \% 34.19 mentol, \% 3.26 mentil asetat, \% 37.32 menton, \% 1.91 mentofuran taşıdığı saptanmıştır (Kromatog. 1).

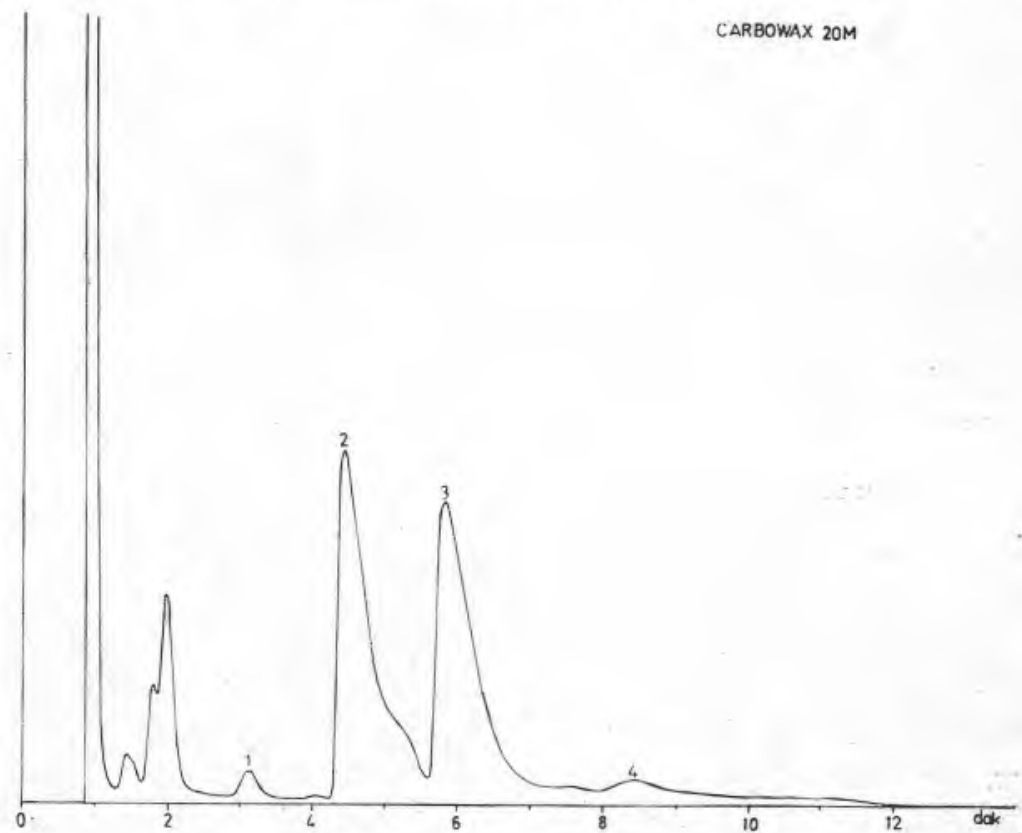

Kromatog. 1- Mentha piperita (Çiçek açmadan önce) uçucu yağının Carbowax 20M kolonundaki gaz kromatogram.

(1) Mentofuran, (2) Menton, (3) Mentol, (4) Mentilasetat.

$B u$ üç denemede, uçucu yağ elde edilen naneler henüz çiçek açmağa başlamışken biçilmiştir. Dördüncü bir denemede bitkiler çiçek açmışken biçilmiş ve bekletmeden distillenerek uçucu yağ elde edilmiştir. Bu örneklerde uçucu yağ verimi \% 1.2 dir. Elde edilen uçucu yağda \% 53.40 mentol, \% 5.89 mentil asetat, \% 16.04 menton, \% 3.93 mentofuran bulunduğu saptanmıştır (Kromatog. 2).

5- Nane çeşit denemeleri: Isparta'daki deneme alanında iki nane türünün ekim denemesi daha yapılmıştır. 


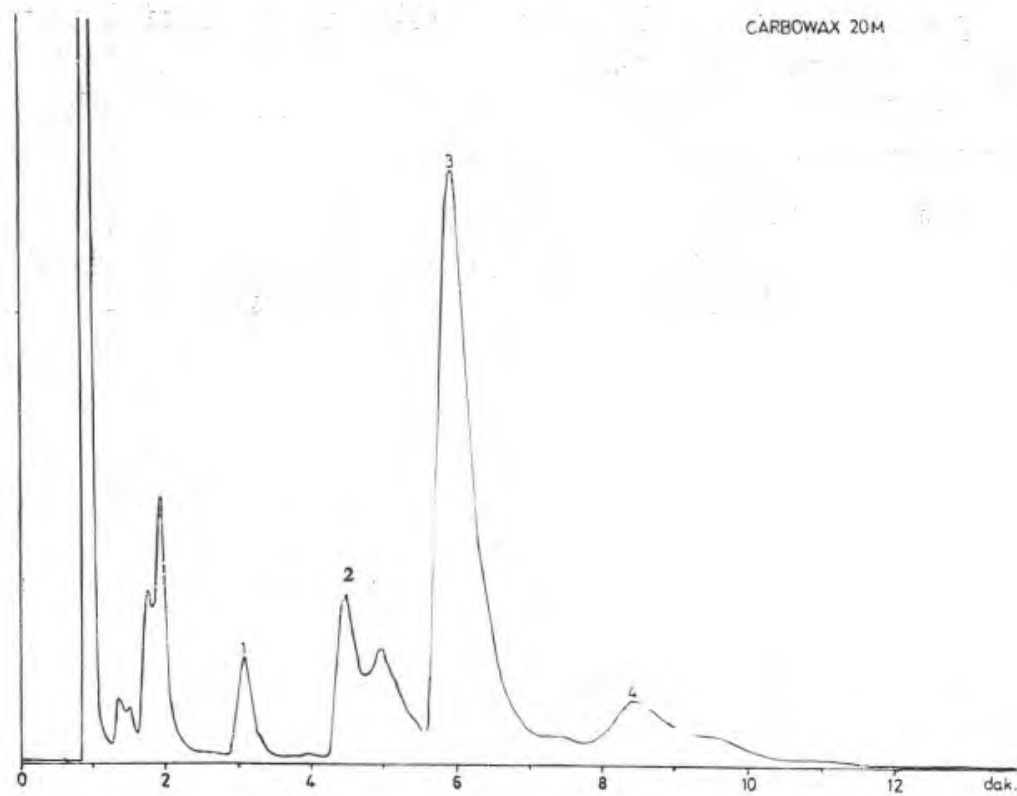

Kromatog. 2- Mentha piperita (Çiçek açmış) uçucu yağının Carbowax 20M kolonundaki gaz kromatogram.

(1) Mentofuran, (2) Menton, (3) Mentol, (4) Mentilasetat

a) Polymentha tipi: 1975 yılında Ege Unniversitesi, Ziraat Fak., Agroekoloji kürsüsünden getirilip dikimi yapılan bu naneler 8.8.1975 tarihinde biçilmiş ve dekara yaş nane verimi $834 \mathrm{~kg}$ olarak hesaplanmıştır. Bu nanelerin uçucu yă̆ verimi \% 0.36 dır.

Elde edilen uçucu yağın analizinde, bu yağın \% 19.78 mentol, $\% 5.12$ mentil asetat, \% 59.43 menton ve $\% 1.58$ mentofuran taşıdığ saptanmışır.

b) Ukraine 541 tipi: Aynı kaynaktan elde edilip ayn zamanda kültürüne başlanan bu naneler 4.8.1975 tarihinde biçilmiş ve dekar başına yaş nane verimi $1200 \mathrm{~kg}$ olarak hesaplanmıştır. Bu nanelerden \% 0.37 oranında alınan uçucu yağ \% 30.79 mentol, \% 5.93 mentil asetat, $\% 37.92$ menton ve $\% 0.78$ mentofuran taşımaktadır.

\section{SONUÇ}

Yapılan tüm denemelerde elde edilen sonuçlar tabloda özetlenmiştir. 
Tablo: Denenen Nane Örneklerinde Verim ve uçucu Yağ Bileşimi

\begin{tabular}{|c|c|c|c|c|c|c|c|}
\hline \multirow[b]{2}{*}{ Deneme } & \multirow{2}{*}{$\begin{array}{l}\text { Dekar başına } \\
\text { verim } \mathrm{Kg}\end{array}$} & \multirow{2}{*}{$\begin{array}{l}\text { Uçucu yağ } \\
\text { verimi \% }\end{array}$} & \multicolumn{5}{|c|}{ Uçucu yağda oksijenli terpenler } \\
\hline & & & $\begin{array}{l}\text { Total } \\
\text { mentol }\end{array}$ & $\begin{array}{l}\text { Serbest } \\
\text { mentol }\end{array}$ & $\begin{array}{l}\text { Mentil } \\
\text { asetat }\end{array}$ & Mentol & Mentofuran \\
\hline Yılda iki biçim (Isparta) & 3000 & - & 49.00 & 44.79 & 4.21 & 29.21 & 3.33 \\
\hline Yılda tek biçim (Isparta) & 2070 & 0.32 & 44.43 & 38.80 & 5.63 & 33.96 & 2.69 \\
\hline Tarlaya tekrar ekim (Isparta) & 815 & 0.38 & 45.46 & 38.63 & 6.83 & 32.32 & 2.54 \\
\hline Seyreltme (Isparta) & 1160 & 0.42 & 44.40 & 38.67 & 5.73 & 33.92 & 1.71 \\
\hline Bekletmeden distilasyon (Ankara) & - & 1.0 & 48.54 & 43.98 & 4.56 & 32.48 & 0.79 \\
\hline Soldurduktan sonra distilasyon (Ankara) & - & 2.4 & 44.12 & 41.07 & 3.05 & 35.37 & 1.06 \\
\hline Kurutulduktan sonra distilasyon (Ankara) & - & 4.0 & 37.42 & 34.19 & 3.26 & 37.32 & 1.91 \\
\hline Çiçek açmı̧ örneklerin distilasyon (Ankara) & - & 1.2 & 59.29 & 53.40 & 5.89 & 16.04 & 3.93 \\
\hline Polymentha (Isparta) & 834 & 0.36 & 24.90 & 18.78 & 5.12 & 59.43 & 1.58 \\
\hline Ukraine 541 (Isparta) & 1200 & 0.37 & 36.72 & 30.79 & 5.93 & 37.92 & 0.78 \\
\hline
\end{tabular}


Yapılan deneme ve analizlerc göre Isparta bölgesinde, Mitcham nanesinden 2 biçim alnmması, üzerinde durulacak bir konudur. Herşeyden evvel dekar başına $2000 \mathrm{~kg}$ yerine $3000 \mathrm{~kg}$ yaş nane elde edilmektedir. Bu da yapilacak ek masrafi fazlasıyla karşılayacak demektir. Elde edilen uçucu yağ verimi bakımından sağlıkh rakamlar elde edilememiş olmasına karşın alınan uçucu yağın \% 49.00 total mentol taşıması bu yağın farmasötik standartlara uygun sayılabileceğini göstermektedir. Tabloda görülen ve tek biçim yapıldığında toplanan nanelerden elde edilen uçucu yağın daha az mentol kapsadığına ilişkin sonuç, biçim sayısı ile değil, biçim zamanı ile ilgilidir. Iki biçim denemesinde ikinci biçim, ilk biçim denemesinden 15 gün sonra yapılmıștır. Bu süre nane uçucu yağında bulunan menton'un bir kısmının daha mentol haline geçmesine neden olmuştur. Gerçekten iki biçim denemesinde elde edilen uçucu yağda menton miktarı azalmıs, mentol ve mentofuran miktan ise yükselmiştir.

Nane dikilmiş tarladan bitkiler söküldükten sonra tekrar nane dikilmesi halinde, yaş nane verimi azalmaktadır. Elde edilen uçucu yağın veriminde ve kalitesinde büyük farklılkk olmamakla beraber yaş nane veriminin önemli ölçüde azalması, aynı tarlanın, tekrar aynı amaçla kullanılma olasılığını ortadan kaldırmaktadır. $O$ halde, Mitcham kültürüne 3 yıl devam ettikten sonra nanelerin buradan sökülüp başka bir tarlaya aktarılması ve eski tarlada da başka bir bitki ekimi yapilması gerekecektir.

Seyreltme, uçucu yağ verimini arttırmakta, fakat uçucu yağ kalitesine bir başkalık getirmemektedir. Denemede dekar başına yaş nane verimi düşmüştür. Seyreltmeden sonra bitkilere yeterli gelişme süresini sağlamak gerekmektedir. $\mathrm{Bu}$, tam olarak sağlanamadığından yaş nane veriminde bir düşüklük meydana gelmiş bulunmaktadır.

Bitkide uçucu yağ verimi üzerinde yapılan araştırmalar çiçek açmış bitkilerde hem uçucu yağ verimi bakımından \% 20 oranında bir artma olduğunu hem de elde edilen uçucu yağda total mentol yüzdesinin 59.29 gibi bir orana yükseldiğini göstermektedir. Buna paralel olarak uçucu yağdaki menton miktarı iyice azalmış ve mentofuran oram da önemli ölçüde artmıştır. Buna göre biçim sırasında çiçeklenme zamanın beklemeğe özellikle dikkat göstermek gerekmektedir. Biçilen bitkiler hemen distillenmemeli, bir gün ve bir gece toprak üzerinde birakılarak soldurulduktan sonra distillenmelidir. Böy- 
lece uçucu yağ verimini $\% 140$ arttırmak olanağı elde edilecektir. Gerçi bu artışı bir kısmı, aslında bitkinin su kaybına bağlı bağıl bir artıştır ama uçucu yağ elde etme sırasında harcanacak enerji miktarının azaltılması yönünden önemi açıktır. Kaldı ki, bu bekletme sırasında, heterozit şeklinde bağlı bulunan bir kısım terpenik alkollerin de açığa çıktığı ve uçucu yağ veriminde gerçek bir artış yarattığı da bilinmektedir.

Biçilen nanelerin kurutulduktan sonra distilasyonu ise uçucu yağ veriminin bağıl artışını sağlamasına rağmen yağda mentol miktarının azalması yönünden uygun bir işlem olarak görülmemektedir.

Ankara'da yetiştirilen nanelerle, Isparta'da yetiştirilenler arasında uçucu yağ verimi bakımindan büyük bir farkhlık var gibi görülmektedir. Fakat, bu denemeleri kendi arasında değerlendirmek gerekir. Çünkü Isparta'da köylünün kolayca sağlıyabileceği araç ve gereçlerle distilasyon yapılmış, verim buna göre hesaplanmıştır. Ankara'da ise toplanan bitkilerde uçucu yağ miktar tayini laboratuvarda Clevenger apareyi ile yapılmıştır. Bu nedenle verim Isparta'dakine oranla çok yüksek görülmektedir,

Kültürü denenen iki nane türü de Mitcham nanesine göre düşük kalitede yağ vermektedirler. Polymentha tipinde hem yaş nane veriminde bir düşüş görülmekte hem de uçucu yağda mentol yüzdesi istenilenin çok altunda hesaplanmaktadir. Ukraine 541 tipi yaş nane verimi bakımından kısmen yüksek bir değer vermekte ise de bu bitkiden de elde edilen uçucu yağda mentol miktarı istenen düzeyde değildir, Bu iki bitkiden elde edilen uçucu yağlar, keton yüzdesi yüksek nane yağları arasında değerlendirilmelidir.

\section{ÖZET}

Orta Anadolu'da yetiştirilen Mitcham nanesinin (Mentha piperita var. officinalis $\mathrm{f}$, rubescens) bazı kültür koşulları incelendi ve uçucu yağ verimini arttırmak için gerekli işlemler araştırıldı.

Kültür denemelerinde Isparta bölgesinde bir yılda iki biçim yapılabileceği, seyreltme ile uçucu yă̆ veriminin arttırılabileceği, ayn tarlaya ikinci defa nane dikmenin faydalı olmıacağı saptandı. 
Uçucu yağ verimini arttırmak ve kaliteyi yükseltmek için bitkinin çiçekli iken toplanması, soldurulduktan sonra su buharı distilasyonuna tabi tutulması gerektiği, kuru drogtan alınan uçucu yağda mentol miktarının düştüğü saptandı.

\section{RESUME}

On a étudié l'huile volatile de la plante fraiche de Mentha piperita var. officinalis $\mathrm{f}$. rubescens cultivée aux environs d'Isparta (Anatolie centrale). Voici les resultats:

Deux coupes successives par an sont possible. La teneur de l'huile volatile s'augmente avec la raréfaction. La première coupe, on doit faire pendant ou bien juste avant la floraison. Pour augmenter la teneur en essence, il faut laisser fletrir 24 heures avant de distiller. Dans l'essence que l'on a obtenu de la plante seche la teneur en menthol est diminue.

\section{LITERATÜR}

1. Alpmen, G., Istanbul, Ecz. Fak. Mec. 11, 95 (1975).

2. Gürgen, A.R., Ankara Yüks. Zir. Enst. Derg., 6, 301 (1946).

3. Gürgen A.R., ibid. 9, 350 (1948).

4. Tanker, M., Eczacılık Bülteni 4, 195 (1962).

5. Tanker, M., Sezik, E., Istanbul, Ecz. Fak. Mec., 1, 55 (1965).

6. Tanker, M., Yenen, M. Ergöz, E., Ankara Ecz. Fak. Mec. 1, 76 (1971). 